\title{
Sobre la recepción de Aretino en España a través de sus traducciones ${ }^{1}$
}

\section{Cesáreo Calvo Rigual}

Universitat de València

Cesareo.Calvo@uv.es

\section{Resumen}

En primer lugar se pasa revista a los escasos estudios que se han ocupado de la recepción de Aretino en la literatura española. Tras ello, se analizan otras posibles vías de penetración de la obra de Aretino en España, como por ejemplo el contenido de los prólogos de algunas de las traducciones al castellano y al catalán hechas entre 1547 y 2000, o bien la selección de textos traducidos. En tercer y último lugar, se estudia la calidad de todas las versiones localizadas. El trabajo se completa con un detallado catálogo de todas las traducciones de obras de Aretino publicadas hasta ahora en España, tanto en castellano como en catalán.

Palabras clave: Aretino, recepción, traducción, España.

\section{Abstract}

Firstly there is a review of the rather few studies which have dealt with Aretino's reception within Spanish Literature. Secondly, an analysis of other possible ways by which Aretino's work has reached Spain; namely, the contents of the prefaces to some of the Spanish and Catalan translations produced between 1547 and 2000, and also the selection of texts translated. Thirdly and finally, a survey of the quality of all versions found. The essay also includes a comprehensive and detailed catalogue of all the translations of works by Aretino published in Spain up to the present, both in Spanish and in Catalan.

Key words: Aretino, reception, translation, Spain.

Marcelino Menéndez y Pelayo, en sus Orígenes de la novela dedicó a Aretino unas escuetas líneas que, entre otras cosas, ponen en relación las Sei gior$n_{a t}{ }^{2}$ con La lozana andaluza de Francisco Delicado, pero subrayan a la vez la casi nula repercusión de su obra en España:

1 Este artículo se enmarca en el Proyecto de Investigación PB-98-1237 financiado por el Ministerio de Educación y Cultura, titulado «La tradición del texto en las versiones españolas de obras literarias italianas» y dirigido por la doctora Ma de las Nieves MuÑIZ MuÑIZ. Se toma como base, reelaborándolo, mi trabajo titulado "Aretino en España» que aparece en la introducción a la edición de Las seis jornadas. La cortesana, Madrid: Cátedra, 2000, p. 67-84, al que se añaden nuevos datos.

2. Dado que esta obra y sus partes han recibido diferentes nombres, no estará de más indicar que me referiré a ellas con los siguientes títulos en italiano: Sei giornate = edición conjun- 
[...] Por la misma razón, nunca fueron populares aquí el nombre ni los escritos de Pedro Aretino. Sus mismas comedias, que valen más que su fama, no fueron imitadas por nadie, y es caso muy raro verlas mencionadas con elogio. Sólo recuerdo este pasaje del prólogo de la Comedia de Sepúlveda, fechada en 1547: «¿Y qué diremos de Pietro Aretino, a quien por la excelencia de su juicio tienen por epíteto en su nombre el Divino? Pues notorio es que lo principal de sus obras son las comedias que hizo».3

Si bien es cierto que Aretino no está demasiado presente en la literatura española, no lo es menos que otros estudiosos han creído ver con posterioridad influencias suyas en autores no tomados en cuenta por Menéndez Pelayo. Así Ana Vian ${ }^{4}$ ha señalado recientemente claras huellas del escritor italiano en el canto VII de El Crotalón de "Cristóforo Gnofoso" (compuesto en 1556), aunque reconociendo la imposibilidad de establecer si el contacto fue directo o mediado por la traducción que Fernán Xuárez hizo de la tercera jornada del Ragionamento en 1547. La estudiosa observa asimismo que lo que en el original es una parodia despiadada de los diálogos humanistas, se convierte en $E l$ Crotalón en un relato ejemplar moralizante, tal como el propio Xuárez sostiene en la declaración de intenciones antepuesta a su adaptación (antes que traducción) de la obra. Por su parte Anna Giordano ha podido constatar más de una analogía entre la producción dramática de Aretino y la de Bartolomé Torres Naharro, uno de los muchos literatos españoles que pululaban por la Italia de la primera mitad del Quinientos; ${ }^{5}$ mientras que V. Gatto y M. Lettieri han estudiado la influencia de Aretino en una comedia de Lope de Vega, ${ }^{6}$ y Margarita Halpine ${ }^{7}$ ha señalado numerosos paralelismos entre La Cortigiana (en su redacción de 1525) y el Buscón de Quevedo (i. e., la afinidad entre los personajes de Rosso y Pablos, la exagerada caracterización de ciertos tipos femeninos, el recurso a la terminología eclesiástica para describir situaciones relativas a la comida o al hambre).

Indudable resulta, por lo demás, la presencia de Aretino en Las lágrimas de Angélica de Luis Barahona de Soto, que del italiano tomó el título y la idea de

ta del Ragionamento y del Dialogo; Ragionamento = Ragionamento della Nanna e della Antonia (1534); Dialogo = Dialogo nel quale la Nanna... (1536). Como es sabido el título Sei giornate se debe a Giovanni Aquilecchia, que lo utiliza en su edición (1969), frente al título tradicional de Ragionamenti que se remonta a la primera edición conjunta de ambas obras del año 1584.

3. Marcelino Menéndez y Pelayo, «Primeras imitaciones de La Celestina», en Orígenes de la novela, Santander: Aldus, 1943, vol. IV, p. 65-66.

4. Ana Vian Herrero, «Pietro Aretino y la cortesana del canto VII de El Crotalón», en Studi Ispanici, Roma: Istituti Editoriali e Poligrafici Internazionali, 1997-1998, p. 57-74.

5. Anna Giordano Gramegna, "Análisis de la Cortesana de Pietro Aretino», en Actas del II Congreso Nacional de Italianistas. El Renacimiento italiano (Murcia, 1984), Universidad de Salamanca, 1986, p. 161-175.

6. V. Gatto, M. LetTieri, "L'Orazia dell'Aretino e El honrado hermano di Lope de Vega», Campi immaginabili, 1991, fasc. III, p. 47-55.

7. Margarita HalPINE, "Aretino's La cortigiana: A Source of Picaresque Elements in Quevedo's Buscón", Romance Review, no 4, 1994, p. 53-63. 
proseguir la historia de Angélica y Medoro allí donde la dejó Ariosto (Orlando Furioso, XXX, 16), aunque dando soluciones diferentes a la empresa. El caso más patente de coincidencia textual, lo constituye la trágica historia de amor relatada en Le lagrime di Angelica, II, 24-77, adaptada (y a trechos traducida) en las estrofas 25-91 del canto IV del poema español. ${ }^{8}$

Mucho menor parece haber sido el eco de Aretino en ámbito catalán si pensamos que únicamente Joan Alegret ha encontrado ciertas semejanzas entre una poesía de Aretino y otra del pintor y poeta de origen griego Pere Serafí, contemporáneo del autor. ${ }^{9}$

\section{Las traducciones y sus prólogos}

Para medir el influjo de Aretino en España, además de su fortuna en términos generales, hemos de recurrir a otro indicador indirecto: ${ }^{10}$ el de las traducciones de sus obras, bastante numerosas aunque desiguales en calidad y discontinuas en el tiempo. En algunas de ellas encontramos, además, prólogos o introducciones que, unidas a otros datos del paratexto y al medio editorial empleado, arrojan luz adicional sobre la recepción reservada al escritor.

La ya mencionada traducción de Xuárez es la primera y casi única de una obra de Aretino en el período áureo de la literatura española. ${ }^{11}$ Las intenciones que guiaban al traductor se plasmaron en dos prolijos prólogos y en unas coplas finales: en los primeros se intentaba justificar — de una forma tan vehemente como para hacer pensar a algunos en una actitud fingida - la decisión de verter al castellano la escabrosa tercera jornada del Ragionamento, justificación, dicho sea de paso, por completo ajena al espíritu de Aretino. Concretamente, para Xuárez era lícito publicar este diálogo sólo en la medida en que podía considerarse como un ejemplo negativo de lo que la juventud debía rehuir. Tenía lugar, en suma, una inversión simétrica de objetivos, puntualmente reflejada en la traducción del texto, que presenta graves manipulaciones a las que me referiré más adelante.

8. Luis Barahona De Soto, Las lágrimas de Angélica, ed. de José Lara Garrido, Madrid: Cátedra, 1981, especialmente p. 46-47 y 224 ss. Ciertamente existen otros precedentes del tema del amor probado — tal como señala Lara (p. 47, n.71) —, como la historia de Gualterio y Griselda del Decamerón o la Leyenda Áurea de Voragine, pero parece indudable la dependencia directa de la Angelica de Aretino. Cfr. G. MolinARO, "Barahona de Soto and Aretino", en Italica, XXXII (1955), p. 22-26.

9. Joan Alegret, «Pietro Aretino, font literària de Pere Serafí", Estudi General (Llengua i Literatura de l'Edat Mitjana al Renaixement), no 11, 1991-1992, p. 81-89. No hemos podido consultar, en cambio, la edición crítica y anotada de la poesía completa de este autor, al cuidado de Romeu Figueras (Barcelona: El Barcino, 2001), aún no distribuida en librería cuando ya estaban escritas estas páginas.

10. Para otros indicadores indirectos, véase la Nota-apéndice al final de este artículo.

11. Como se señalará más adelante, el bibliógrafo Nicolás Antonio recoge una traducción de las obras Umanità di Cristo, Vita di Maria Vergine y los Sette salmi della penitenza di David, que atribuye a Pedro Rocha. 
Las demás traducciones aretinianas pertenecen ya al siglo XX. La mayor parte de ellas están precedidas por prólogos en los que se intenta acercar la figura y la obra del autor al público español, pero sin ir más allá de un repertorio de prejuicios y estereotipos (tanto personales como tomados de la tradición), al que se sustrae sólo la introducción del malogrado italianista Ángel Chiclana a su versión de La Cortigiana y del Marescalco. El primero de estos prólogos, publicado en 1900 (aunque perteneciente en rigor al siglo XIX), es el de J.M. Llanas Aguilaniedo a su traducción de La Cortigiana, ${ }^{12}$ una premisa tan breve como poco significativa, donde lo único que emerge es la evidente simpatía del traductor por Aretino. El segundo se debió a José López Barbadillo, ${ }^{13}$ y acompañó la traducción de esa misma obra, aparecida en 1914: en él hallamos nuevamente una favorable semblanza biográfica del autor, ${ }^{14}$ pero acompañada por la justificación del carácter libertino de la obra: ${ }^{15}$ un lugar común que, junto con el anticlericalismo militante, compartirán tantos otros traductores y editores (será también el caso de Bergua, del que me ocuparé dentro de poco). Así, López Barbadillo se declaraba movido a traducir el Ragionamento no sólo por «el más puro deleite espiritual», sino sobre todo por el valor documental de la obra, al igual que, según sus palabras, habían hecho antes otros escritores franceses, ingleses y alemanes.

La traducción de José Bruno, publicada por Juan B. Bergua en 1933, ${ }^{16}$ no contiene la habitual biografía del autor; en su lugar encontramos reproducida una larga carta del filósofo Jaime Balmes (que parece haber pasado desapercibida hasta ahora a la crítica aretiniana) donde se describe el ágape con el que fue agasajado en 1845 en la ciudad de Bruselas por el nuncio apostólico, monseñor Pecci, más tarde papa con el nombre de León XIII. En dicha carta Balmes subraya el aprecio de monseñor por la obra de Aretino, frente a quienes abominaban de ella en nombre de un mal entendido moralismo. La traducción de Bruno sería reeditada sin apenas cambios en 1978 por el mismo Bergua, el cual añadió a la misiva de Balmes un extenso prólogo, muestra de una personalidad que me atrevería a calificar de polémica y algo excéntrica, donde, mezclando anticlericalismo y tono moralista, defiende la obra

12. Pietro Aretino, Coloquio de las damas y La cortesana, Madrid: Rodríguez Serra, 1900, p. 117119.

13. Los diálogos del divino Pietro Aretino. Por vez primera puestos en lengua castellana. Traducción de Joaquín López Barbadillo, Madrid: Joaquín López Barbadillo, 1914-1915, 3 vols.

14. Véase en qué términos concluye dicha semblanza: «Murió viejo y feliz. Fue un canalla magnífico, que convirtió en rayos de gloria los puñados de fango. Hizo escarnio de Dios, de los hombres, del Amor, de la Muerte... ¡Pero se rebeló contra el destino, y le venció! Nació en un hospital y acabó en un palacio. En este siglo aretinesco en que no hay Aretinos, concluiría en una cárcel; y por eso yo quiero amasarle una estatua con el ilustre fango de su vida, y tener el honor de divulgar su gloria» (p. XVI).

15. Dicho prólogo se titula así: «Discurso preliminar en que se trata de la naturaleza y plan de estos Diálogos, se explica su gran fama, se muestra su excelencia y se disculpa su libertinaje» (p. XVII).

16. Pietro Aretino, Los ragionamenti. Diálogos putañescos, Madrid: Librería Bergua, 1933. 
y la vida del escritor italiano en cuanto fiel reflejo de su tiempo para cuyo entendimiento juzga inadmisible aplicar la óptica actual. El prólogo acaba con un curioso diálogo inventado en el que Aretino cobra vida y conversa con Bergua sobre los hechos que estaban acaeciendo durante la transición democrática española, diálogo que recuerda otros más antiguos, como por ejemplo el mantenido por Machiavelli con Dante en el Discorso o dialogo intorno alla nostra lingua.

De los demás prólogos — dejando a parte el de Ángel Chiclana y el estudio introductorio de Giordano-Calvo, respondentes a criterios de edición propios de un clásico- poco puede sacarse en limpio. Caso extremo digno de mención resulta en tal sentido el de Aldo Berti, ${ }^{17}$ que descarga un virulento ataque contra la persona de Aretino, a quien separa completamente de su obra, mientras que dentro de ésta parece apreciar sobre todo La Cortigiana. ${ }^{18}$

\section{La selección de los textos y la calidad de las versiones}

El rastreo de las traducciones de Aretino en castellano y en otras lenguas de España arroja resultados curiosos y hasta cierto punto sorprendentes, tratándose de un autor que durante siglos fue perseguido e incluso ignorado en su propio país. Buena parte de su popularidad se debe a un interés (a veces morboso) por las obras más escabrosas, concretamente las Sei giornate (y dentro de ellas el Ragionamento), o los Sonetti lussuriosi, consideradas aún hoy por muchos editores simplemente como clásicos de la literatura erótica o pornográfica, capaces de atraer al público interesado en este tipo de temas más por su contenido que por sus valores literarios. En efecto, si se examina la lista de traducciones que ofrecemos en apéndice, se podrá constatar que la mayor parte corresponden a las citadas obras, aunque también han suscitado interés algunas piezas teatrales como La Cortigiana y el Marescalco.

La situación descrita explica también que las ediciones de Aretino en espanol presenten una marcada dicotomía: por un lado las poquísimas que se guían por un interés filológico o altamente divulgativo, en cuyo caso se alcanza, como es obvio, un nivel aceptable de rigor y corrección; por el otro, las pertenecientes a la llamada literatura de masas, concebidas con meros fines comerciales y casi siempre plagadas de incorrecciones cuando no caracterizadas por operaciones fraudulentas (desde plagios hasta prácticas ilícitas de diferente tipo).

En cuanto a la calidad de las versiones, valdrá la pena dedicar alguna atención a las más significativas, empezando por las Sei giornate, cuya historia editorial resulta ser más compleja que las demás.

17. Coloquio de damas, en Giovanni Boccaccio, Pietro Aretino, El Decamerón. Coloquio de damas. La cortesana, Buenos Aires: EDAF, 1961, p. 795-800.

18. Así acaba su prólogo: «Acabó su vida en diciembre de 1557. El hijo de una ramera, nacido en un hospital, murió, viejo y feliz, en un palacio, rodeado de comodidades y riquezas. Fue un canalla magnífico que supo trocar el fango en oro, los harapos en principesca púrpura, mediante el hábil manejo de su pluma y de su lengua» (p. 800). 
La prioridad cronológica en el corpus de las traducciones aretinianas corresponde, como hemos dicho, a Fernán Xuárez, que ofreció una versión reducida de la tercera jornada del Ragionamento. Dicha «reducción» obedece a dos factores: por una parte, la supresión de todas las palabras, expresiones o pasajes más explícitos desde el punto de vista sexual; por otra, a la eliminación de cualquier referencia religiosa. Se podrá, pues, comprender fácilmente que la integridad de la obra original quede en esta versión gravemente comprometida. Las numerosas alteraciones del texto están determinadas, además, por la finalidad didáctico-moralizante declarada al inicio del volumen, en manifiesto contraste con el espíritu del autor italiano.

Valdrá a este respecto la pena reproducir la parte del prólogo en la que Xuárez justifica su trabajo como traductor:

Si por ventura alguno, mas curioso de lo que conuiene, murmurando acusasse al tradutor deste colloquio diziendo no auerlo romançado al pie de la letra de como esta en toscano, quitando en algunos cabos partes, y en otros renglones, e assi mesmo mudando nombres e alguna sentencia y en algun otro lugar diziendo lo mesmo que el auctor, aunque por otros modos, a esto respondo que en diuersos lugares deste colloquio falle muchos vocablos, que con la libertad que ay en el hablar y en el escreuir donde el se imprimio se sufren, que en nuestra España no se permitirian en ninguna impression, por la deshonestidad dellos. De cuya causa, en su lugar acorde de poner otros mas honestos, procurando en todo no desuiarme de la sentencia, aunque por diferentes vocablos, excepto en algunas partes donde totalmente conuino huyr della, por ser de poco fructo y de mucho escandalo y murmuracion ("El Yntérprete al lector"). ${ }^{19}$

La traducción de Xuárez sufrió una accidentada peripecia desde sus primeras ediciones, sobre las que no todo parece estar claro aún, y pasó, entre otras vicisitudes, por su inclusión en el Índice de la Inquisición española en 1559 (un destino tocado a la restante obra de Aretino en el de Roma de 1564); se podría explicar así que aunque en dos años se hicieran cuatro impresiones (y puede que aún más), casi no queden hoy ejemplares de ella. A pesar de todas las dificultades, el interés por el Coloquio de las damas debió de mantenerse, sin embargo, vivo, puesto que lo vemos reeditado nuevamente, de forma clandestina, en 1607.

El trabajo de Xuárez ha sido juzgado, en general, severamente, a causa de escasa fidelidad al original; cabe, sin embargo, señalar que ese hecho fue apreciado de forma opuesta por J. López Barbadillo y M. Menéndez Pelayo, el primero mostrándose sumamente crítico con las manipulaciones moralizantes del traductor; el segundo favorable a ellas. Los pasajes que transcribimos a continuación eximen de mayores comentarios:

19. Cito por la ed. de Bonilla y Sanmartín: Pietro Aretino, Coloquio de las Damas, en Marcelino MenÉndez Pelayo, Orígenes de la novela, NBAE, 21, Madrid: Bailly/Baillière, 1915, vol. IV, p. 250-277. 
Hay infinitos cambios de detalles; se truecan caprichosamente los objetos que juegan en la acción; la obra entera se ve salpicada de interrupciones pseudofilosóficas, comentarios de una psicología rudimentaria, refranes privativamente castellanos sin relación con el original, y añadiduras que, aunque no desentonen en el libro, más cerca están de recordar nuestra española Celestina que los Ragionamenti italianos (López Barbadillo). ${ }^{20}$

El traductor tomó todo género de precauciones para hacer pasar aquel diálogo, que él mismo empieza por calificar de «abominable cieno corrompedor de toda salud de la casta limpieza». Pero la misma insistencia y extravagancia de sus excusas hace dudar de la pureza de su intención, porque los libros de historias profanas, como las de Amadís y Tristán, de que habla en uno de sus prefacios, nada tienen que ver con la literatura a que pertenece el Coloquio. Lo que no puede negarse es que le adecentó bastante, quitándole algunas obscenidades, aunque todavía quedaron las suficientes para que fuese con mucha razón prohibido en los Índices del Santo Oficio. Otras cosas alteró, procurando españolizar el libro. La traducción no es de las peores que por entonces se hacían del toscano, pero es apelmazada y carece de la viveza y gracia del original (Menéndez Pelayo). ${ }^{21}$

Tras un vacío de tres siglos largos, en 1900 verá la luz una nueva edición del Coloquio, en una colección de libros picarescos editada por Rodríguez Serra, que se valió de la de 1607. Seguidamente Menéndez Pelayo reprodujo en sus Orígenes de la novela la de 1548. Por desgracia, en sucesivas ediciones (Madrid, Ágata, 1994; Xuárez bis: plagio de Aldo Berti) los editores no fueron tan escrupulosos y rehicieron a su antojo la antigua versión, con resultados francamente deplorables.

Las traducciones de Paniagua y de León, a pesar de que no parecen basarse en la versión de Xuárez - entre otras cosas porque sólo hubiera servido como base para una parte de su trabajo, pues se atienen a las jornadas segunda y tercera del Ragionamento - son, curiosamente, muy similares, en cuanto a pobreza linguíística, a la traducción (o semi plagio) de Berti. En efecto, al igual que Xuárez, eliminan todo pasaje donde el sexo está más explícitamente presente y rehacen el texto de manera desenvuelta (sobre todo León).

Antes de la publicación de la primera edición completa de las Sei giornate (Bruno 1933) aparecerán dos traducciones del Ragionamento muy diferentes entre sí, las de López Barbadillo (1914-14) y la de Heras (1917). La primera es una de las más cuidadas y elaboradas, como lo demuestra no sólo la esmerada edición en tres volúmenes, sino también la presencia de más de 150 notas

20. Los diálogos del divino Pietro Aretino. Por vez primera puestos en lengua castellana. Madrid: Joaquín López Barbadillo, 1914-15, vol. III, p. 138-139. Se trata de una extensa nota en la que López Barbadillo reproduce los prólogos de la traducción de Xuárez y la estudia con cierto detalle (de hecho es el único análisis, junto con el de Guidotti, op. cit., que se ocupa con cierto detenimiento de ella).

21. Marcelino Menéndez y Pelayo, Orígenes de la novela, Santander: Aldus, 1943, vol. IV, p. 66-67. 
al texto. ${ }^{22}$ Pero la preocupación del traductor parece ser más la de ofrecer un texto de un fuerte regusto literario que la de aproximarse al original respetando sus características lingüísticas. En efecto, el lenguaje empleado es el de tono más retórico entre las traducciones consideradas, cosa que no se corresponde con el estilo original, caracterizado más bien por un fuerte expresionismo que por un componente preciosista. ${ }^{23}$ La traducción de Heras muestra, en cambio, una mayor fidelidad al lenguaje aretiniano e incluye algunas notas — pocas—, generalmente acertadas.

La primera traducción completa de las Sei giornate se debe a José Bruno (1933), y a ella se remitirán las ediciones de Bergua (1978) y el plagio de J. Santina (1940), que la reproducen sin apenas modificaciones. Esta versión es esencialmente fiel al texto aretiniano, salvo por lo que respecta, una vez más, a la reproducción de su rico lenguaje, que a menudo se empobrece con equivalentes sólo aproximados, sobre todo cuando se trata de trasladar términos y expresiones poco frecuentes, tan abundantes en las obras de Aretino. Cabe advertir, en fin, que en este caso el traductor se preocupa de añadir algunas notas encaminadas a facilitar la comprensión del texto, y que existe una importante diferencia entre la traducción del Ragionamento - visiblemente deudora de la de López Barbadillo_-, y la del Dialogo — que, careciendo de precedentes, resulta mucho más pobre, con un texto plagado de errores de todo tipo.

Elemento no secundario en el estudio de las traducciones, es el del texto fuente en el que se fundó cada versión. Como he indicado más extensamente en otro lugar, ${ }^{24}$ en el caso de las traducciones españolas de las Sei giornate (ya sea completas o parciales), las ediciones empleadas fueron las siguientes:

a) La primera edición tanto del Ragionamento della Nanna et della Antonia (París, Ubertinus Mazzola Art. \& Medicine Doctor, 1534) como del Dialogo di M. Pietro Aretino, nel quale la Nanna... (Turín, P.M.L., 1536). Este es el punto de partida de la edición de referencia actual, la de Aquilecchia; sobre ella está hecha la traducción de Giordano-Calvo (2000).

b) La obra titulada Opera nova del divo et unico signor Pietro Aretino... (Nápoles, s.n., 1534), que es una edición clandestina de la tercera jornada del Ragionamento: de ésta parte la traducción de Xuárez y sus sucesivas ediciones y plagios.

c) La primera edición conjunta de las seis jornadas, bajo el título de La prima parte de' ragionamenti di $M$. Pietro Aretino y La seconda parte de’ ragionamenti di M. Pietro Aretino (Bengodi, 1584 [Londres, John Wolf, 1584]):

22. Bien es verdad que muchas de ellas son excesivamente prolijas y no siempre pertinentes.

23. Como se ha señalado, López BARBADILlo es también traductor de la comedia Il Marescalco, para la que se sirve de un ejemplar de 1536 conservado en la Biblioteca Nacional, una «edición pésimamente puntuada y llena de innumerables erratas que hacen el texto poco menos que inintelibigle» (p. xxv). Contrasta esta afirmación con el mayor rigor y preocupación filológicas presentes en su traducción del Ragionamento.

24. Pietro Aretino, Las seis jornadas. La cortesana, Madrid: Cátedra, 2000, p. 81-83. 
en ella se basan Paniagua, López Barbadillo, Heras, Bruno (y sus secuelas: Bergua y Santina) y León.

Otra obra que ha gozado de las preferencias de los traductores - al menos a juzgar por el número de las publicadas- son los Sonetti lussuriosi (o Sonetti sopra $i$ «XVI modi»), muy diferente de la anterior, no sólo por ser en verso, sino porque el nutrido armamentario metafórico de las Sei giornate se ve transformado aquí en un lenguaje explícito y transgresivo, abiertamente pornográfco. Al igual que la obra que acabamos de citar, los Sonetti lussuriosi han tenido también una transmisión textual bastante accidentada; fruto de ella es la diversidad de fuentes disponibles, que en el caso de las cinco traducciones reseñadas, corresponden a las siguientes ediciones:

a) Ediciones anteriores a 1982 (también otras posteriores de carácter popular), que constituyen una tradición adulterada del texto: de ella derivan las traducciones de Bergua (1933) y Villena (1991).

b) Edición de Lawner (1984): ${ }^{25}$ siguen esta edición $\mathrm{Merlo}^{26}$ — por motivos evidentes - y la de un anónimo (1992).

c) Edición de Aquilecchia (1992): ${ }^{27}$ en ella se basa Ávila (1999). Esta edición recoge sólo los 14 sonetos conservados en el único ejemplar sobreviviente del siglo XVI, desestimando la posibilidad de las otras ediciones de integrar esta falla con dos sonetos de dudosa procedencia. ${ }^{28}$

De las traducciones de estos sonetos, ${ }^{29}$ tres se presentan en edición bilingüe: las de Merlo, Villena y Ávila; todas ellas reproducen el metro original - soneto con estrambote- y al menos dos mantienen la rima (Bergua y

25. I modi nell'opera di Giulio Romano, Marcantonio Raimondi, Pietro Aretino e Jean-Fréderic-Maximilien de Waldeck, a cura di Lynne Lawner, traduzione di Nicola Crocetti, Milano: Longanesi, 1984. Angelo Romano, citado por Ávila en su edición (p. 139, n. 19), en su reseña de la edición de Lawner, critica el hecho de que ésta se arrogue la primacía en la edición crítica de esta obra y que además no cite el aparato textual de Aquilecchia, que parece haber seguido en buena medida.

26. Sobre esta traducción, Ávila afirma que «no es sino una traducción a la letra de la edición inglesa The sixteen Pleasures de 1984, en donde, sin embargo, se advierte nítidamente el soporte que le ofrece la edición italiana publicada el mismo año» (op. cit., p. 138).

27. Pietro ARetino, Poesie varie, a cura di Giovanni Aquilecchia e Angelo Romano, Roma: Salerno, 1992; sin embargo, la edición de base y sus criterios filológicos se encontraban ya en Giovanni AQUILECCHIA, "Per l'edizione critica dei "Sonetti sopra i 'XVI modi" di Pietro Aretino", Filologia e critica, VII (1982), p. 267-282.

28. Acertadamente, Ávila (op. cit., p.139) se pregunta si en el caso de Lawner es lícita tal inclusión, dado que se trata de «un trabajo que pretende restaurar los textos aretinianos».

29. Únicamente he podido consultar BERGUA (1933), Anónimo (1992) y Ávila (1999). Como ya se indicó en anteriores notas, hay reseñas de José Francisco RuIz de las traducciones de Villena (1991) y Ávila (1999). Por otra parte en la introducción de ésta última se pasa revista de forma crítica a las anteriores de BerguA, Merlo y Villena, lo que nos dispensa de tratarlas aquí por extenso, pues además compartimos los acertados juicios de Ávila. 
Anónimo: con mayor acierto la segunda). Pablo Luis Ávila, en su edición de 1999, se ocupa de las tres versiones castellanas anteriores a la suya, juzgándolas negativamente, sobre todo las dos primeras. ${ }^{30}$ En efecto, el caso de Bergua es especialmente sangrante, pues en la práctica se trata de una recreación empobrecedora, que sustituye el léxico directo del original por deslucidos eufemismos.

La traducción anónima catalana de 1992 es la única que ha pasado inadvertida hasta hoy a la crítica. Se trata de una traducción que en general respeta el original y sus características, aunque realizando sacrificios significativos e incurriendo en errores a veces vistosos al querer mantener la rima además del metro, cosa que no hace Ávila en su traducción. ${ }^{31}$

No resta sino comentar brevemente las escasas traducciones de las comedias de Aretino emprendidas en España, las cuales se reducen a dos piezas: Il Marescalco y La cortigiana. De la primera se ocuparon López Barbadillo (1908) y Chiclana (1989). Ya en el título de sus respectivas traducciones hay una importante diferencia: Comedia del herrador para el primero, El caballerizo para el segundo (que juzga equivocada la opción de su predecesor). La de L. Barbadillo es la más literal, ${ }^{32}$ mientras que Chiclana opta deliberadamente por introducir algunos elementos ausentes del original a fin de aumentar su «teatralidad»: incremento de deícticos, acotaciones, etc. Para su versión catalana de la segunda pieza, Vallverdú se inclinará, en cambio, por la redacción de $L a$ cortigiana de 1525, considerada por él más espontánea; y de hecho el resultado logra mantener la fuerza y la frescura del texto de Aretino. Por último, merece un breve comentario la de J.M. Llanas, que sigue la redacción de 1534, pero que, como el proprio traductor confiesa, se ateniene demasiado literalmente

30. José Francisco RuIZ reseña la traducción de VILLENA en El Observador del 20 de febrero de 1992 y la de Ávila en el $A B C$ cultural del 23 de octubre de 1999.

31. Como muestra, véanse algunos de los errores de diferente tipo que he detectado en la traducción del soneto II: caro vecchione / estimat ancià (v.1) [se ve obligado a renunciar al sufijo por la rima]; cazzo / cigala (v.2) [uso de un eufemismo en lugar de la palabra explícita piu usada más adelante; probablemente por causa del metro; hay que señalar la dificultad que entraña mantener éste en una lengua como el catalán, en cuyo léxico abundan muchísimo más que en italiano las palabras mono- y bisilábicas]; boccone / menjar (v.5) [mucho menos concreto; también por motivos de rima]; pan unto / pa ben torrat (v.6); C'huomo non è, chi non è bugerone / que no és un home aquell qui trampa no fa (v.8) [parece un error por incomprensión de bugerone "homosexual»]; In potta io ve 'l farò questa fiata / Al cony et fotré això que ara ja m'esclata (v.9) [o bien el traductor no ha entendido questa fiata o bien —-más probable_ha preferido traducir así para mantener la rima en -ata]; il cazzo / el piu roig (v.12) [amplificación para crear una rima con boig del v.12]; E chi vòl / I qui vulgui (v.12) [cambio de modo verbal]; è pazzo / és un gran boig (v.12); E crepi nel palazzo / Ser cortegiano, e aspetti che 'l tal muoia / Que rebenti al seu estoig /qui és cortesà i esperi morir al palau (vv. 15-16) [en catalán los versos resultan incomprensibles, pues el cortegiano, de esperar a que alguien se muera, pasa a esperar él mismo la muerte; por otra parte la reestructuración de los versos para mantener la rima con los versos anteriores resulta también catastrófica].

32. Cfr. lo dicho anteriormente a propósito de su traducción del Ragionamento. 
al original, ${ }^{33}$ incurriendo a menudo en calcos que dan lugar a inexactitudes y malentendidos. ${ }^{34}$

Es hora de extraer algunas conclusiones de lo dicho hasta aquí. En su época, la obra de Aretino suscitó un interés relativo en España, aunque no tan escaso como había creído Menéndez Pelayo. Prueba de ello el hecho de que sólo una minúscula parte de sus escritos haya sido vertida al español después de cuatro siglos. Por contra, el tercer Ragionamento tuvo un inmediato éxito que se reflejó en cuatro ediciones en pocos años y una reimpresión al inicio del siglo siguiente.

Con todo, el verdadero interés por Aretino ha llegado sin duda en el siglo XX (ya desde 1900), y responde a dos tipos de motivaciones: una puramente comercial centrada en sus obras y pasajes más obscenos, y otra que podríamos calificar de "culta», más atenta a los valores de tipo literario e incluso conceptual de sus obras. El mayor interés se ha concentrado en tres de ellas, por este orden: las Sei giornate, los Sonetti lussuriosi y La cortigiana. Conviene precisar, sin embargo, que, por obvios motivos (la dictadura franquista), la publicación de obras de Aretino en español se concentra en dos épocas: las primeras décadas del siglo y las últimas. Añadamos que, si en su momento la obra del escritor «maldito» estuvo sujeta a polémicas, plagios, atribuciones falsas, etc., en el siglo XX su recepción en España se ha visto sometida también a diferentes vicisitudes, que incluyen entre otras cosas varios plagios.

Por lo demás, pese a las numerosas traducciones reseñadas, como hemos dicho, buena parte de las obras de Aretino no han merecido hasta ahora en nuestro país una traducción: entre ellas se encuentran sus escritos religiosos (con la excepción de la posible traducción de Pedro Rocha indicada en décimo lugar del apartado siguiente), sus poemas épicos (dejando a un lado la adaptación de los fragmentos de Angelica tomados por Barahona de Soto), tres de sus comedias (Lo Ipocrito, La Talanta, Il Filosofo), su única tragedia (L'Orazia), otros dos diálogos (Dialogo del giuoco, Ragionamento delle corti) y sus afortunados libros de Lettere, además de otros textos menores y dispersos.

En fin, aunque el ámbito lingüístico catalán no ha sido ajeno a la obra aretiniana, y cuenta con versiones o cuidadas o felices, su empeño ha sido menor

33. «...para dejar paso a la comedia, cuya versión hice, inspirado en la buena intención de dar a conocer con la mayor fidelidad posible obras que tanta resonancia tuvieron en otro tiempo, respetando las crudezas del lenguaje y abusando tal vez de la traducción literal, para no separarme un punto del espíritu que las dictó» (op. cit., p. 119).

34. Algunos ejemplos tomados del Acto I, 1-2: Roma è coda mundi / Roma es el rabo del mundo; non arei mai creduto ch'ella fosse stata più bella di Siena / nunca hubiera creído fuese mejor que Siena; ma tu non dici che ci vuol bene l'Imperadore / pero no dices que allí quiere bien el emperador; SENESE. Io vi stimo. MACO. Quanto? SENESE. Un ducato. MACO. Ti vo' bene ora, sai? / Senés. Os quiero. Micer Maco. ¿Cuánto? Senés. Un ducado. Micer Maco. Te vuelvo mi afecto, ¿sabes?; intendo il favellar da Roma / entiendo la parla de Roma; SENESE. La mi quadra, la, la mi va, la m'entra. MACO. Quando mi porrete mano? / SENÉs. Me agrada; eso me entra, me conviene. MICER MACO. ¿Cuándo me pondréis mano? 
que el de habla castellana en términos cuantitativos. Las motivaciones básicamente cultas de este interés explican que las obras traducidas hayan sido $\mathrm{La}$ Cortigiana y los Sonetti lussuriosi.

\section{APÉNDICE}

\section{Catálogo de traducciones}

Ofrecemos aquí por primera vez un catálogo completo de traducciones al español y al catalán (no nos consta ninguna traducción ni al gallego ni al eusquera), ordenadas cronológicamente, indicando primero el año de publicación del original, luego el de la traducción: ${ }^{35}$

1. La Cortigiana (redacción de 1525): ${ }^{36}$

[Vallverdú 1985] Traducción al catalán de Francesc VALLVERDÚ: La cortesana, en: Niccolò Machiavelli, Pietro Aretino, Angelo RuZzante, Giordano Bruno, Teatre del Renaixement, Barcelona: Edicions 62-La Caixa, 1985, p. 87-210.

[Giordano-Calvo 2000] Traducción de Anna Giordano y Cesáreo Calvo: La cortesana, en: Las seis jornadas. La cortesana, Madrid: Cátedra, 2000, p. 513-625.

2. Sonetti lussuriosi o Sonetti sopra $i$ «XVI modi» (1527): ${ }^{37}$

[Bergua 1933] Traducción de Juan B. BerguA, en dos ediciones: Sonetos lujuriosos, en: Los ragionamenti. Diálogos putañescos, Madrid: Libr. Bergua, $1933,{ }^{38}$ p. 381398; Madrid, Juan B. Bergua, 1978, p. 477-494.

[Merlo 1990] Traducción de María Merlo: Lynne Lawner, Pietro Aretino, Los 16 placeres. Las cortesanas del Renacimiento, Madrid: Ediciones Temas de Hoy (Biblioteca Erótica), 1990 [edición, notas y comentarios: Lynne LAWNER; traducción de los sonetos: María MerLo; prólogo de George SZABO].

[Villena 1991] Traducción de Luis Antonio DE VILLENA: Sonetos lujuriosos, Madrid: Visor, 1991.39

35. En el Manual del librero español e hispanoamericano de Palau y Dulcet, s.v. Aretino, se señala una traducción más de una obra de Aretino, que hemos preferido no incluir entre las que siguen por ser muy pobres los datos que de ella se ofrecen: Las mujeres casadas, Barcelona, s.n., s.a. Debe tratarse probablemente de una traducción de la Jornada II de los Ragionamenti (quizá una nueva edición de la traducción de dicha jornada de López Barbadillo que citamos más adelante).

36. Se omite el nombre del autor (Pietro Aretino) cuando no aparece bajo otra forma o junto a otros autores. Las ediciones sucesivas aparecen precedidas por punto y coma en el mismo parágrafo.

37. En ocasiones fueron publicados también con el título de Corona di cazzi. Aunque excede de los límites geográficos de este trabajo, señalamos otra traducción, que figura en el catálogo de la British Library: Sonetos lujuriosos \& pasquines del Aretino, seguidos de otros sonetos lujuriosos, dudas amorosas y otras dudas amorosas de autores anónimos de tradición aretinesca y de un soneto de Giorgio Baffo, traducción de Sarandy Cabrera, Montevideo: Vintén, 1991.

38. En nuestra introducción a la traducción de Las seis jornadas. La cortesana indiqué erróneamente la fecha de 1934, siguiendo otras referencias (incluso la de la edición del mismo Bergua de 1978); en realidad el colofón (único lugar en el que se menciona la fecha de edición) dice: «Esta obra se terminó de imprimir [...] el día 30 diciembre 1933».

39. Cfr. la reseña de José Francisco Ruiz en El Observador del 20 de febrero de 1992. 
[Anónimo 1992] Traducción anónima: Sonets luxuriosos, Barcelona-Venecia, s.n., s.a. [1992]. ${ }^{40}$ Se trata de una rara traducción al catalán.

[Ávila 1999] Traducción de Pablo Luis ÁviLA: Sonetos sobre los «XVI modos», Palma de Mallorca: José J. DE OlaÑETA-Universitat de les Illes Balears, 1999 [Introducción de Giancarlo DEPRETIS, preliminar de José SARAMAGO; edición, traducción, estudio y notas de Pablo Luis DE ÁviLA]. ${ }^{41}$

\section{Il Marescalco (1533):}

[López Barbadillo 1908] Traducción de Joaquín LÓPEz BARBADILlo: Comedia de El Herrador, del azote de principes y gran demostracion de vicios y virtudes... por vez primera puesta de la lengua toscana en castellano por J.L.B., Madrid: M. PÉREZ VILLAVICENCIO, 1908.

[Chiclana 1989] Traducción de Ángel CHIClANA: El caballerizo, en: La comedia de la corte. El caballerizo, Madrid: Espasa-Calpe, 1989, p. 201-309.

\section{La Cortigiana (redacción de 1534):}

[Llanas 1900] Traducción de J. M. Llanas Aguilaniedo: La cortesana, en: Coloquio de las damas y La cortesana. Madrid: Rodríguez Serra, 1900, p. 120-381; Giovanni BocCaCcio, Pietro Aretino, El Decamerón. Coloquio de damas. La cortesana, Buenos Aires, EDAF, 1961, p. 875-1082 [reediciones de este volumen: Buenos Aires: EDAF, 1962, 1964, 1967, 1968, 1970, 1971; Madrid: EDAF, 1971]; La cortesana. Coloquio de damas, Madrid: EDAF, 1977, p. 17-187.

[Chiclana 1989] Traducción de Ángel CHICLANA: La comedia de la corte, en: La comedia de la corte. El caballerizo. Madrid: Espasa-Calpe, 1989, p. 49-200.

\section{Ragionamento (1534):}

[Barbadillo 1914-15] Traducción de Joaquín LÓPEZ BARBADILLO: Los diálogos del divino Pietro Aretino. Por vez primera puestos en lengua castellana. Madrid: Joaquín LOPEZ BARBADILLO, 1914-15, 3 vols.; ${ }^{42}$ Madrid: Viuda de López Barbadillo, 1923 [ed. facsímil: Madrid: Akal, 1978].

[Heras 1917] Traducción de Eusebio Heras: Diálogos picarescos sobre la vida de las monjas, la vida de las casadas y la vida de las cortesanas, Barcelona: E. Heras editor, [1917]. ${ }^{43}$

\section{Jornada I del Ragionamento (1534):}

[Diéguez 1920] Traducción de R. DiéGUEZ: La suave vida de las monjas, Barcelona, $1920 .{ }^{44}$

40. Debemos las noticias sobre esta traducción a la amabilidad del profesor José Francisco RuIz, de la Universitat Pompeu Fabra de Barcelona, en cuya biblioteca se encuentra esta rara edición. Su fecha de publicación se deduce del prólogo firmado por las enigmáticas iniciales A.M.J.

41. Hay reseña de José Francisco RuIZ en el $A B C$ cultural del 23 de octubre de 1999.

42. Palau cita una segunda edición de la traducción del primero de los diálogos (Jornada I de los Ragionamenti): La licenciosa vida de las monjas, Madrid: Impr. Yagües, 1920; y otra del tercero (Jornada III de los Ragionamenti): La infame vida de las cortesanas, s.l., s.n., 1917.

43. Palau cita la siguiente obra, que debe ser una reedición de esta traducción: Diálogos picarescos sobre la vida de las monjas, mujeres casadas y cortesanas. Barcelona: Maucci. Tanto de ésta como de las citadas en la nota anterior, no se han podido localizar ejemplares.

44. Datos tomados de Palau: no he podido localizar ningún ejemplar de esta traducción, que con toda probabilidad corresponde a la primera jornada del Ragionamento. 


\section{Jornadas II y III del Ragionamento (1534):}

[Paniagua 1908-11] Traducción de Ramiro G. PANIAGUa: Vida de las casadas y de las cortesanas, Valencia: Prometeo (Clásicos del amor), 1908-1911; ${ }^{45}$ Vida de las casadas y las cortesanas, Valencia: Prometeo, 1916; Diálogo de casadas y cortesanas, México: Premiá, 1979.

[León 1971] Traducción de Jacinto LEÓN IGNACIO: Vida de las casadas y de las cortesanas, en Erotikon II. Selección de relatos galantes y amorosos, Barcelona: Eds. 29, 1971; Barcelona: Eds. 29, 1990.

\section{Jornada III del Ragionamento (1534):}

[Xuárez 1547] Traducción de Fernán XuÁREz: Coloquio de las Damas. Coloquio del famoso y gra [n] demostrador de vicios y virtutudes (sic) Pedro Aretina (sic), en [e]l qual se descubren las falsedades, tratos, engaños y hechizerías de que usan las mugeres enamoradas alos simples y auna los muy auisados hombres que dellas se enamoran. Agora nueuamente traduzido de lengua toscana en castellano por el Beneficiado Fernán Xuárez, vezino y natural de Seuilla. ${ }^{46}$ De esta traducción áurea pueden señalarse al menos 5 ediciones antiguas (probablemente no las únicas): ${ }^{47}$ Sevilla, Juan DE LEÓn, 1547; s.l., s.n., 1548; ${ }^{48}$ Zaragoza, Diego HernándeZ, 1548; Medina del Campo, Pedro DE CASTRO, 1549; s.l., s.n., $1607.4^{49}$ Durante el siglo XX ha sido reeditada con diferente fortuna en varias ocasiones con títulos ligeramente diferentes: Coloquio de las damas del famoso y gran demostrador de vicios y virtudes Pedro Aretino. Agora nuevamente traducido de la lengua toscana en castellano por el Beneficiado Fernán Xuárez, vecino y natural de Sevilla, en Coloquio de las damas y La cortesana, Madrid: Rodríguez Serra (Colección de libros picarescos, 2), 1900, p. 1-113 [reproducción fiel de la edición de 1607];50 Coloquio de damas, Madrid: Ambrosio Pérez y cía, $1901 ;{ }^{51}$ Coloquio de las Damas, en M. Menéndez PelaYO, Origenes de la novela, NBAE, 21, Madrid: Bailly/Baillière, 1915, vol. IV, p. 250-77: la edición corrió a cargo del erudito A. Bonilla y Sanmartín [reproducción fiel de la edición: s.l., s.n., 1548]; El coloquio de las damas, en: Francisco DELICADO, La lozana andaluza seguida por El coloquio de las damas de El Aretino,

45. La referencia de esta primera edición está tomada de Gloria GUIDOTTI, «Da "La vita delle puttane" al "Colóquio" [sic] de las damas", en El Renacimiento Italiano. Actas del II Congreso Nacional de Italianistas (Murcia, 1984), Salamanca: Universidad, 1986, p. $247-$ 257.

46. Se reproduce el título completo de la edición de 1548 (s.l, s.n.), a partir de la reproducción facsímil de la portada y del frontispicio recogidos en D.R. RHODES, «Pietro Aretino in Spain", Gutenberg-Jahrbuch, no 64, 1989, p. 138-139). Este artículo, a pesar de coincidir en su título con el presente trabajo, es sólo una reseña bibliográfica de las ediciones antiguas del Coloquio.

47. Las ediciones segunda y tercera, extremadamente raras, son señaladas por Rhodes, op. cit.

48. Según Rhodes, op. cit., p. 138-139, sería: Sevilla, Dominico de Robertis, 1548.

49. Rhodes, op. cit., p. 141, afirma que es difícil saber dónde fue impreso este libro, aunque lo más probable es que no fuera en España, sino en otro país, quizás Holanda. Hace referencia a 9 ejemplares conservados de esta edición.

50. Según Guidotti, op. cit., p. 248, existe una reedición hecha en Madrid en 1901.

51. Citado por Palau y Dulcet, s.v. Aretino, aunque no hemos podido localizar ningún ejemplar. 
Barcelona: Lorenzana, 1965 (reed. en Pamplona: Larraiza, 1970); ${ }^{52}$ Coloquio de las damas, Madrid: Ágata, $1994 . .^{53}$

[Xuárez bis] Traducción de Aldo BERTI: en realidad es una versión «actualizada» de la de Xuárez, que no cita en ningún momento, por lo que puede considerarse un plagio. Existen numerosas ediciones y reimpresiones: Giovanni BoCCACCIO, Pietro Aretino, El Decamerón. Coloquio de damas. La cortesana, Buenos Aires: EDAF, 1961, p. 803-873 [reediciones de este volumen: Buenos Aires: EDAF, 1962, 1964, 1967, 1968, 1970, 1971; Madrid: EDAF, 1971]; La cortesana. Coloquio de damas, Madrid: EDAF, 1977, p. 189-247.

\section{Sei giornate (1534-1536):}

[Bruno 1933] Traducción de José BRUNO: Los ragionamenti. Diálogos putañescos, ${ }^{54}$ traducidos por José Bruno, Madrid: Librería Bergua, 1933; Los Ragionamenti (Diálogos putañescos), ${ }^{55}$ traducción de Juan B. Bergua, Madrid: Juan B. Bergua, 19782; ${ }^{56}$ Los ragionamenti (diálogos amenos), versión española de José Santina. MadridBuenos Aires: Librería Perlado, $1940 .{ }^{57}$ De esta versión con el nombre de J. Santina (o Sastina en otras) existen tres ediciones, con el título de Dialogos amenos: Barcelona: Bruguera, 1977; id., 1982; Barcelona: Libros y Publicaciones Periódicas (La sonrisa vertical, 38-39), 1984, 2 vols. En realidad no se trata de tres traducciones diferentes, sino de una sola, pues tanto Bergua como Santina siguen a Bruno; el proceder de Bergua está parcialmente justificado en el prólogo de su edición, mientras que el de Santina constituye un caso flagrante de plagio, pues no cita a Bruno.

52. No hemos podido consultar esta edición, pero atendiendo al título y al hecho de que se edite junto a la Lozana andaluza es de suponer que será una reedición de la de 1900, puesto que también allí aparece pubicado junto a La lozana andaluza, como no 1 de la Colección de libros picarescos.

53. Se menciona a Fernán Xuárez en la introducción, pero sin más noticias que permitan saber qué edición se reproduce. El libro está ilustrado con fotos eróticas que parecen de principios del siglo XX.

54. El título completo es: Los Ragionamenti (diálogos putañescos). Vida de las casadas, cortesanas y monjas. La educación de Pipa. Las charranadas de los hombres. La rufianería. Los diálogos lujuriosos. Los sonetos lujuriosos.

55. El título completo es: Los Ragionamenti (diálogos putañescos). Vida de las casadas, cortesanas y monjas. La educación de Pippa. Las astucias y picardias de los hombres. La rufianería. Los sonetos lujuriosos.

56. En el inicio de la «Noticia preliminar», con su peculiar estilo, Bergua nos dice: «Pronto hará cuarenta y cinco años que mandé a la imprenta la primera edición de los "Ragionamenti". La traducción no era mía a excepción de "Los sonetos lujuriosos", pues el que tradujo lo demás dijo que no se comprometía a ponerlos en verso. Lo malo fue que ni siquiera me enteré (pues abrumado de trabajo - mi jornada no era de ocho horas, sino de dieciséis y a veces más horas al día - no tuve tiempo de leer la traducción que había hecho) de que en los "Ragionamenti", había trozos que hubieran debido también ser traducidos en verso, como están en el original; total, que ahora he tenido que hacerlo yo, así como revisar toda la traducción, para esta nueva edición que ahora ofrezco.» La revisión a la que alude Bergua fue realmente superficial, casi inexistente, y en lo que respecta a los versos, hubiera sido mejor dejarlos como estaban en la edición de 1933 (en la que, contrariamente a lo afirmado por Bergua, sí están traducidos como tales versos), pues al menos vierten fielmente los originales, mientras que los de Bergua se alejan en exceso de aquellos.

57. Datos tomados del catálogo de la Library of Congress. 
[Giordano-Calvo 2000] Traducción de Anna Giordano y Cesáreo Calvo: Las seis jornadas, en: Las seis jornadas. La cortesana, edición y traducción de, Madrid: Cátedra, 2000, p. 111-511.

10. Della umanità di Cristo (1535), La vita di Maria Vergine (1540), I sette salmi della penitentia di David (1534):

[Rocha s.a.] Traducción de Pedro Rocha: De la humanidad de Christo, De la Vida de Nuestra Señora, Los siete salmos penitenciales. ${ }^{58}$

\section{NOTA APÉNDICE}

Un índice complementario de la fortuna de Aretino en España lo constituyen las menciones del autor que pueden encontrarse en diferentes obras, literarias o no, desde el siglo XVI hasta nuestros días. En tal sentido, la búsqueda realizada en el Corpus Diacrónico del Español (CORDE) puesto a disposición por la Real Academia Española, que recoge miles de textos de los más diversos tipos de toda la historia de nuestra lengua, arroja un resultado poco alentador: en primer lugar se confirma la escasa presencia del nombre de Aretino en la memoria de nuestros escritores, con pocas excepciones; en segundo lugar, la perpetuación de su fama como autor maldito o maldiciente. Entre los testimonios aducidos sobresalen los de un contemporáneo (González de Oviedo) y los de Valle-Inclán. Damos a continuación algunos ejemplos, que van de 1552 a 1907 (los hay posteriores, pero los omitimos por ser menos significativos, además de por obvias razones de espacio): «Veys aquí cómo se escupía primero la mano, e cómo se puede e deue creer que qujen así mató al Perote, mejor mataría a los duques ques dicho. En vn tractado que se intitula Habla de Pedro Aretino en su toscana lengua, Pedro Aretino no ygnorando lo ques dicho, dize que Peroto, músico joueneto, fue degollado en las haldas de Alexandre 6o., al qual se avía acogido.» (G. FERnÁndeZ De Oviedo, Batallas y quinquagenas, 1535-1552). "AlCAIDE Ninguna del mundo ay más que Rroma en ese caso, Pedro Aretino porque concurren la ocasión, la ynorançia, el fraude, la auariçia, la prodigalidad, la arrogançia, el odio, el fauor, la concupisçiençia [sic], la adulaçión, la embidia, la mentira, la ingratitud, la injuria, la merita [sic por mentira], la disimulaçión, la inestabilidad, la calupnia, e la poca vergüença e ningún temor de Dios, en que se incluyen todos los males del mundo. Bien dize Pedro Aretino todo lo ques dicho y añade que en los mílites de Christo está la perfiçión, la nesçesidad, el peligro, la sospecha, el themor, el dolor, el llanto, la malenconía, el lamento, la vergüença, el fastidio, el afán, la fatiga, la enemistad, con todo el rresto de las miserias. Y dize más, que si se pudiese estu-

58. Noticia extraída de la excelente Tesis Doctoral de Lola BECCARIA, Bibliografía de las traducciones del italiano al castellano (siglos XV, XVI y XVII), que a su vez cita a Nicolás ANTONIO, Biblioteca Hispánica nova, II, p. 231-232. No he podido localizar esta traducción. Pedro Rocha sería autor de otras dos traducciones del italiano: de la Fiammetta y del Corbaccio. 
diar en los fauores como en las leyes, los estudiantes no se quitarían jamás de los libros, porque qujen ha fauor ha rriquezas.» (G. FERNÁNDEZ De OvIEDO, $i d$.). «El Duque de Nájera, por hacerle una burla, estando con él en Benavente, acordó de hacerla desta manera: que hace una carta fingida con una memoria de libros nunca oídos ni vistos ni que se verán, los cuales enviaba Pedro Aretino, italiano residente en Venecia, el cual, por ser tan mordaz y satírico, tiene salario del Pontífice, Emperador, Rey de Francia y otros Príncipes y Grandes, y en llegando el tiempo de la paga, si no viene luego, hace una sátira o comedia o otra obra que sepa a esto contra el tal. / Esta carta y memoria de libros venía por mano de un mercader de Burgos, en la cual carta decía que en recompensa de tan buena obra como a Su Señoría había hecho Pedro Aretino, que sería bien enviarle algún presente, pues ya sabía quién era y cuán maldiciente. La carta se dio al Conde, y la memoria, y como la leyese y no entendiese la facultad de los libros, ni aun el autor, mostróla al Duque como a hombre más leído y visto, el cual comienza a ensalzar la excelencia de las obras, y que luego ponga por obra de gratificar tan buen beneficio a Pedro Aretino, que es muy justo. El Conde le preguntó que qué le parescía se le debía enviar. El Duque respondió que cosa de camisas ricas, lençuelos, toallas, guantes aderezados y cosas de conserva y otras cosas de este jaez. En fin, el Duque señalaba lo que más a su propósito hacía, como quien se había de aprovechar de ello más que Pedro Aretino. El Conde puso luego por la obra el hacer del presente, que tardaron más de un mes la Condesa y sus damas y monasterios y otros partes, y hecho todo, enviólo a hacer saber al Duque, y dase orden que se lleve a Burgos, para que desde allí se encamine a Barcelona y a Venecia, y trayan los libros de la memoria; la cual orden dio después mejor el Duque, que lo hizo encaminar a su casa y recámara. Y andando el tiempo, vínolo a saber el Conde, y estovo el más congoxado y desabrido del mundo con la burla del Duque, esperando sazón para hacerle otra para satisfacción de la recibida. La cual, procurando y poniendo por obra, se vino a hacer así, creyendo la hacía al Duque.» (Luis DE PINEDO, Libro de chistes, 1550). «...y no estimando en Italia grandes Príncipes, ni teniendo nombre, solamente a un pintor van a llamar el Divino Michael Angelo como hallaréis en cartas que os escribió Aretino maldiciente de todos los señores cristianos» (Manuel Denss, Traducción de De la pintura antigua de Francisco de Holanda, 1563). «Alzad las faldas y atrancad los charcos / porque no os salpiquéis en el camino / de los que cantan la del conde Alarcos. // No sois tan grave vos como Aretino / ni como aquel que del mosquito y pulga / cantó tras las refriegas del latino.» (Pedro Liñán DE RIAZA, Poesías, 1607). «Bajar de grado en grado se podría, por Eutropio, Vopisco, Marcelino, a las guerras de Italia y de Suría; el Sabélico, Bembo y Aretino, el Mauroceno, Corio, Justiniano, Jovio, Dávila, Franqui, Gichardino, la institución moral, el cortesano, y, si Su Santidad os lo concede, los impíos Machiavelo y el Polano.» (Bernardino De Rebolledo, Conde de Rebolledo, Ocios, 1650-1660). «...erudito humanista Gaspar Barthio, quien habiendo nacido en Custrin el año de 1587, y manifestado desde su infancia un ingenio precoz y una memoria maravillosa, estudió con mucho fruto y lucimiento en 
varias academias y universidades de Alemania [...] y hasta para la traduccion del Pornodidáscalo de Pedro Aretino se asegura que no se valió del original, sino de una version castellana. Este empeño, esta aficion extremada, y una aplicacion tan vehemente á la lectura de nuestras novelas, llegaron á trastornar la cabeza de Barthio...» (Martín Fernández Navarrete, Vida de Miguel de Cervantes Saavedra, 1819). "iPobre Concha! Sobre sus labios perfumados por los rezos, mis labios cantaron los primeros el triunfo del amor y su gloriosa exaltación. Yo tuve que enseñarle toda la lira: Verso por verso, todo el rosario de sonetos de Pietro Aretino. Aquel capullo blanco de niña desposada, apenas sabía murmurar el primero.» (Ramón María DEL VALLE-InClán, Sonata de otoño. Memorias del Marqués de Bradomín, 1902). "Concha movía la cabeza con gracioso enfado, al mismo tiempo que apoyaba un dedo sobre sus labios pálidos: / -No te permito que poses ni de Aretino ni de César Borgia. / La pobre Concha era muy piadosa, y aquella admiración estética que yo sentía en mi juventud por el hijo de Alejandro VI, le daba miedo como si fuese el culto al Diablo. Con exageración risueña y asustadiza me imponía silencio...» (Ramón María DEL VALLE-INCLÁN, id.). «Un lecho antiguo de lustroso nogal, tálamo clásico donde los hidalgos matrimonios navarros dormían hasta llegar a viejos, castos, sencillos, cristianos, ignorantes de aquella ciencia voluptuosa que divertía el ingenio maligno, y un poco teológico, de mi maestro el Aretino.» (Ramón María Del VALLE-InClán, Sonata de invierno. Memorias del Marqués de Bradomín, 1905). "ARLEQUín Bien decís. No la sublime poesía, que sólo canta de nobles y elevados asuntos; ya ni sirve poner el ingenio a las plantas de los poderosos para elogiarlos o satirizarlos; alabanzas o diatribas no tienen valor para ellos; ni agradecen las unas ni temen las otras. El propio Aretino hubiera muerto de hambre en estos tiempos.» (Jacinto BENAVENTE, Los intereses creados, 1907). 